\title{
Carbon dioxide induces minor antioxidant responses in Eucalyptus urophylla chloroplasts
}

\author{
Amanda Cristina Baldassi ${ }^{1} \cdot$ Bruna Marques dos Santos ${ }^{1} \cdot$ Tiago Santana Balbuena $^{1}$
}

Received: 2 February 2018 / Accepted: 10 August 2018 / Published online: 16 August 2018

c) Springer-Verlag GmbH Germany, part of Springer Nature 2018

\begin{abstract}
Key message Minor effect on the chloroplast antioxidant proteins was detected in Eucalyptus urophylla cultivated in high- $\mathrm{CO}_{2}$ atmosphere.

Abstract Global climate change can significantly alter plant cell metabolism. A higher atmospheric $\mathrm{CO}_{2}$ scenario may be beneficial for $\mathrm{C} 3$ plants through the stimulation of photosynthesis. This predicted increase in the rate of carbon assimilation may also increase the expression of enzymes involved in the antioxidant cellular defense. Here, we studied the responses of the chloroplastic antioxidant system of Eucalyptus urophylla plants cultivated in a high- $\mathrm{CO}_{2}$ condition. Plants exposed to a high concentration $(980 \mathrm{ppm})$ of $\mathrm{CO}_{2}$ showed an increase in the $\mathrm{H}_{2} \mathrm{O}_{2}$ concentration and MDA content in relation to those cultivated at 410 and $680 \mathrm{ppm}$. With the discovery proteomics approach used herein, we identified 19 chloroplastic antioxidant proteoforms and pinpointed differentially regulated isoforms of an ascorbate peroxidase and a superoxidase dismutase upon cultivation in a high- $\mathrm{CO}_{2}$ atmosphere. Our data indicate that the $\mathrm{CO}_{2}$ stimulus induces only minor changes in the antioxidant metabolism of E. urophylla chloroplasts.
\end{abstract}

Keywords Antioxidants $\cdot$ Chloroplast $\cdot \mathrm{CO}_{2} \cdot$ Eucalyptus $\cdot$ Proteomics

According to Earth System Research Laboratory (ESRL) Global Monitoring Division (2017), the atmospheric $\mathrm{CO}_{2}$ concentration has increased considerably in the last decades: from $315 \mathrm{ppm}$ in 1958 to $408 \mathrm{ppm}$ in 2017, the highest $\mathrm{CO}_{2}$ concentration ever recorded at the Mauna Loa Observatory. If $\mathrm{CO}_{2}$ emissions continue to increase, the Earth's atmospheric $\mathrm{CO}_{2}$ concentration could reach the remarkable concentration of $985 \mathrm{ppm}$ in the year 2100 (IPCC Panel 2014). Although there is no current consensus on the impact of this global prediction, the increasing $\mathrm{CO}_{2}$ concentration scenario may be beneficial for most plant species, especially for those employing the $\mathrm{C} 3$ photosynthetic pathway, as they depend

Communicated by Heckathorn.

Electronic supplementary material The online version of this article (https://doi.org/10.1007/s00468-018-1750-8) contains supplementary material, which is available to authorized users.

Tiago Santana Balbuena

tsbalbuena@yahoo.com.br; tsbalbuena@fcav.unesp.br

1 Department of Technology, School of Agriculture and Veterinary Sciences, São Paulo State University (UNESP), Jaboticabal, SP, Brazil on a high $\mathrm{CO}_{2}: \mathrm{O}_{2}$ ratio to counterbalance losses due to the photorespiration process.

It is generally accepted that, in addition to the direct modulation of plant growth though photosynthesis, $\mathrm{CO}_{2}$ stimulus may also impact abiotic stress responses. Currently, there are two parallel and potentially complementary hypotheses that sustain the idea that $\mathrm{CO}_{2}$ could alleviate stress effects: the antioxidant hypothesis and the relaxation hypothesis (reviewed by AbdElgawad et al. 2016). While the former relies on the hypothesis that an increase in the $\mathrm{CO}_{2}$ concentration would promote a fast defense response due to the higher availability of carbon molecules for antioxidant molecule biosynthesis, the latter relies on a decreased production of reactive oxygen species (ROS) and antioxidant molecules due to the stimulation of the carboxylase activity of $\mathrm{RuBisCO}$ over the oxygenation process. As there are plenty of reports that give support to both hypotheses (AbdElgawad et al. 2016), it is important to evaluate the effect of $\mathrm{CO}_{2}$ on the antioxidant system on a case by case basis.

Although not limited to them, plant antioxidant enzymes play a fundamental role in the control of ROS homeostasis. Such enzymes can be identified and their expression quantified by large-scale analysis, such as proteomics, which 
combines advanced separation techniques, mass spectrometry and bioinformatic tools to characterize proteins in complex mixtures. This technology becomes even more powerful if targeted to a specific cell compartment, such as in subcellular proteomics, which explores a specific cell compartment and the processes that occur within it. Here, we evaluated the changes in the abundance of chloroplast antioxidant proteins of Eucalyptus urophylla caused by a $\mathrm{CO}_{2}$-enriched atmosphere (980 vs $410 \mathrm{ppm}$ ).

Under abiotic stress, ROS production in plants is elevated, which may lead to an imbalance in the cellular homeostasis if not regulated by antioxidant metabolism. To evaluate the oxidative status of $E$. urophylla leaves under $\mathrm{CO}_{2}$ stimulus, we cultivated young plants ( 90 days old) in plant growth chambers with controlled conditions (temperature adjusted at $27{ }^{\circ} \mathrm{C}$ and photoperiod of $12 \mathrm{~h}$ ) and $\mathrm{CO}_{2}$ concentrations at 410, 680 and $980 \mathrm{ppm}$. After 30 days of growth, plants presented small but significant differences in the $\mathrm{H}_{2} \mathrm{O}_{2}$ and MDA concentrations (Fig. 1). The $\mathrm{H}_{2} \mathrm{O}_{2}$ concentration and the MDA content reached the highest levels in the plants grown at $980 \mathrm{ppm} \mathrm{CO}_{2}$ concentration. As the levels observed at the concentration of $680 \mathrm{ppm}$ were similar
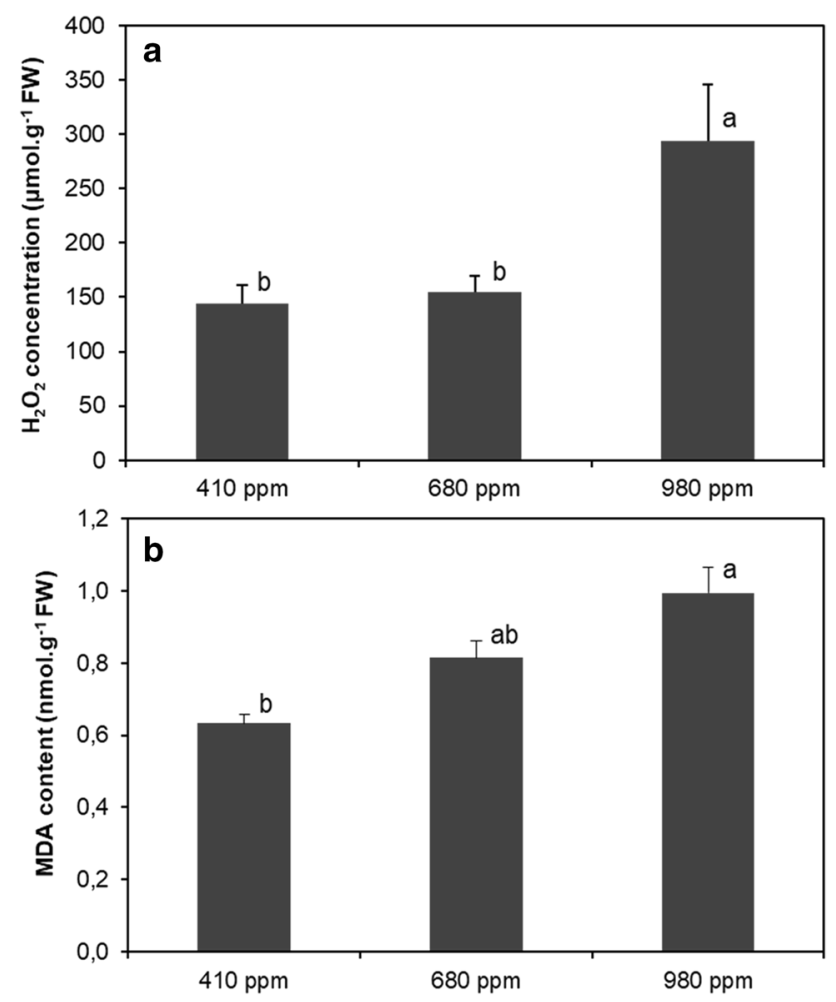

Fig. 1 Concentrations of $\mathrm{H}_{2} \mathrm{O}_{2}$ (a) and malondialdehyde (MDA) (b) of E. urophylla leaves from plants cultivated for 30 days in growth chambers with controlled $\mathrm{CO}_{2}$ concentrations $(410,680$ and $980 \mathrm{ppm})$. Different letters indicate significant differences according to Tukey's test $(p<0.05)$. Standard errors of the mean from three biological replicates are also indicated to the control, the results indicate that the plants showed a high oxidative stress only when submitted to a $980-\mathrm{ppm}$ condition. Although the $\mathrm{CO}_{2}$ effect on oxidative metabolism has already been predicted in several plant species (Kumari et al. 2013; Farfan-Vignolo and Asard 2012; Liu et al. 2016; Singh and Agrawal 2015), our data suggest the existence of a $\mathrm{CO}_{2}$ concentration threshold within the range of 680 and 980 ppm for triggering ROS stress in E. urophylla plants.

Finding the key players in antioxidant response requires a multi-step investigation that usually starts with an untargeted, discovery-driven approach. If $\mathrm{CO}_{2}$ acts as an elicitor for the biosynthesis of antioxidant molecules, an increase in the abundance of those metabolites would be expected when cells are challenged by an abiotic stress. In the absence of an environmental stressor, $\mathrm{CO}_{2}$ stimulus alone could lead to an increase in oxidative damage, acting itself as a stressor, or alleviate ROS production by inhibition of photorespiration. We used large-scale proteomics from isolated chloroplast extracts (Fig. 1S) to identify and relatively quantify the abundance of chloroplast antioxidant proteins from plants exposed to two $\mathrm{CO}_{2}$ concentrations: 410 and $980 \mathrm{ppm}$. In addition to mass spectrometry data analyses, we carried out a stringent data mining approach for plastid localization of antioxidant proteins identified through database searches. From a total of 30 identifications involved in the antioxidant defense, a small sub-set of 19 proteins met the criteria of having high sequence homology with at least one plant plastid database, and having a primary sequence indicating chloroplast localization (Table 1). It is worth noting that of the 19 chloroplastic antioxidant proteins identified here, 15 were thioredoxin-related (TRX) proteoforms. This high fraction of TRX identifications reflect the abundant representation of genes coding this enzyme in the genome of the reference species (Eucalyptus grandis) used here and the key role of this class of enzymes in controlling the redox status of a myriad of protein species. Although TRX forms were the most abundant molecules identified in the present study, two copies of ascorbate peroxidases (Eucgr.F00373.1, Eucgr.F04344.1), one copy of Fe-superoxide dismutase (Eucgr.K00110.6) and one copy of dehydroascorbate reductase (Eucgr.J01595.1) were also confidently identified in the E. urophylla chloroplastic protein extracts (Tables 1, 1S).

An up-regulation, induced by $\mathrm{CO}_{2}$ stimulus, within the antioxidant sub-proteome described here was only detected for two proteins: a thylakoid ascorbate peroxidase (Eucgr. F04344.1) and the Fe-superoxide dismutase 2 (Eucgr. K00110.6) (Fig. 2). Both protein species presented a statistically significant difference in the relative abundance criteria used here (Normalized Spectral Abundance FactorNSAF, Paoletti et al. 2006) according to the Kruskal-Wallis test $(p<0.05)$. The fact that APX and SOD levels were significantly higher when plants were exposed to $980 \mathrm{ppm}$ treatment may be an indication of a high production of the 


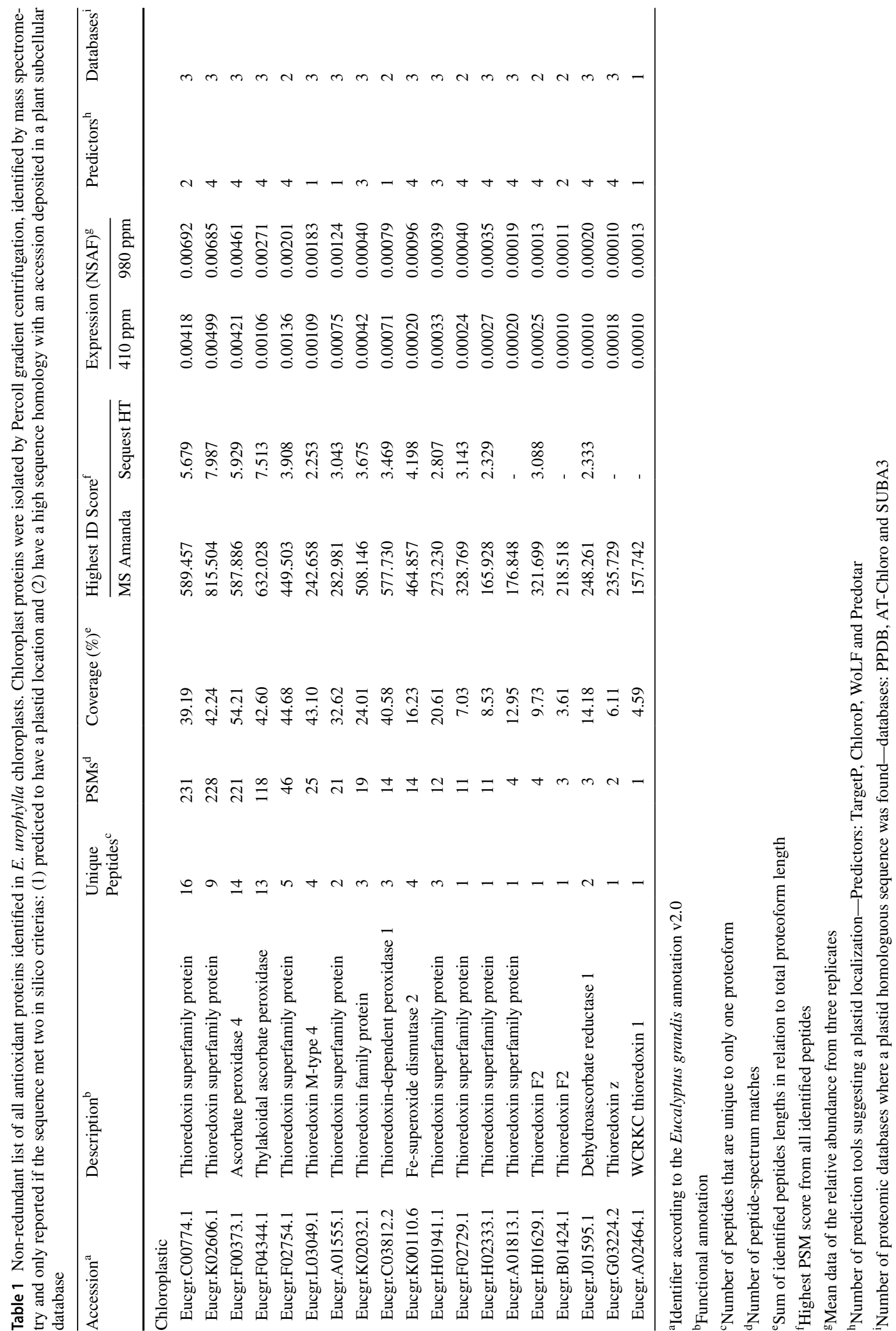




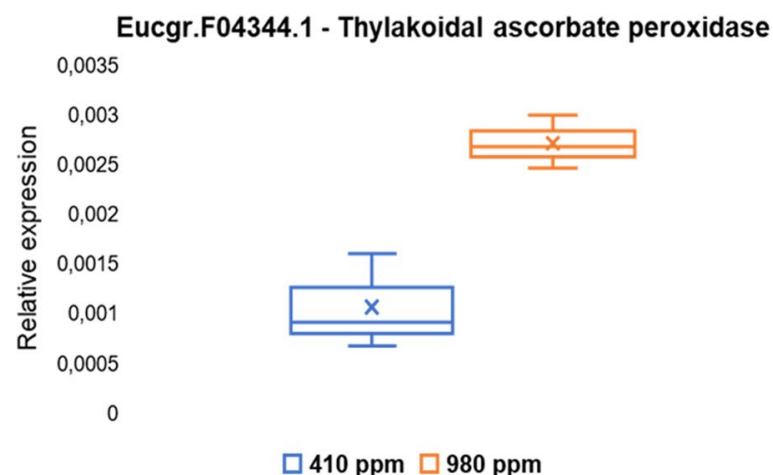

Fig. 2 Expression profiles of the antioxidant proteins Eucgr.F0344.1 and Eucgr.K00110.6 identified as differentially regulated, according to the Kruskal-Wallis test $(p<0.05)$, in young leaves of E. urophylla

superoxide radical $\left(\mathrm{O}_{2}{ }^{-}\right)$within the cells upon $\mathrm{CO}_{2}$ stimulus, leading to the higher expression of the SOD enzyme, and consequently generating a large amount of $\mathrm{H}_{2} \mathrm{O}_{2}$. One of the main ROS neutralization pathways in plants is the ascorbate-glutathione cycle, in which APX is the enzyme responsible for neutralizing $\mathrm{H}_{2} \mathrm{O}_{2}$ into $\mathrm{H}_{2} \mathrm{O}$. Overproduction of $\mathrm{H}_{2} \mathrm{O}_{2}$ by SOD may also lead to overexpression of the APX protein under this stress condition. These data corroborate with the antioxidant responses observed for other plant species (Zlatev et al. 2006; Hu et al. 2008; Mishra et al. 2013) and may be used as a possible indicator of stress for E. urophylla plants cultivated in high atmospheric $\mathrm{CO}_{2}$ concentration. However, it is worth mentioning that the low number of differentially regulated proteins from $E$. urophylla chloroplasts may also indicate that other cellular compartments are playing an equal or a major role in the antioxidant response against $\mathrm{CO}_{2}$ stimulus, as an increase in $\mathrm{H}_{2} \mathrm{O}_{2}$ and MDA levels was seen in plants exposed to $980 \mathrm{ppm}$ concentration (Fig. 1). Additionally, the minor effect of the high $\mathrm{CO}_{2}$ cultivation on the chloroplast antioxidant proteins identified in the present study indicates that it is very unlikely that $\mathrm{CO}_{2}$ induces a standby antioxidant defense that could rapidly respond to oxidative damage induced by other stressors.

In the present communication, we described a differential response in the oxidative status of young E. urophylla plants cultivated in controlled conditions with variations in $\mathrm{CO}_{2}$ concentration according to the last IPCC predictions. Using a proteomics-driven approach, we qualitatively and quantitatively reported what are probably the most abundant antioxidant proteoforms found in E. urophylla chloroplasts. We are aware that the stringent identification criteria used here penalized the chloroplast proteome coverage and, thus, a holistic overview of the $\mathrm{CO}_{2}$-induced alterations. Conversely, protein identifications and quantitative data reported here are of high confidence and strict enough to preferentially consider only major changes induced by the atmospheric $\mathrm{CO}_{2}$. Our data suggest that $\mathrm{CO}_{2}$ may contribute to a
Eucgr.K00110.6 - Fe superoxide dismutase 2
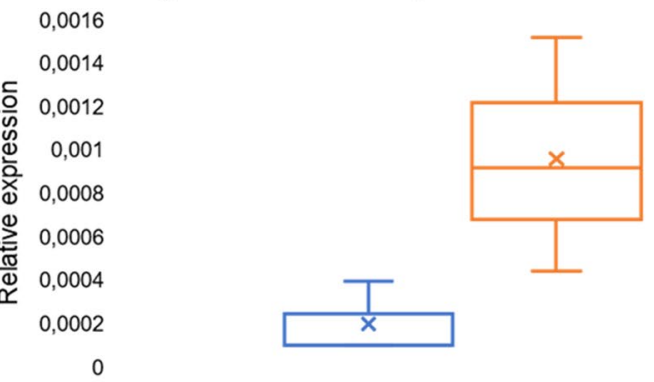

$\square 410 \mathrm{ppm} \square 980 \mathrm{ppm}$

grown at $\mathrm{CO}_{2}$ concentration of 410 and $980 \mathrm{ppm}$. Distribution of data is illustrated as color-coded boxplots: blue for plants cultivated at $410 \mathrm{ppm}$ and orange for plants cultivated at $980 \mathrm{ppm}$

higher tolerance to abiotic stress through metabolic means other than a direct induction of the biosynthesis of antioxidant proteins. However, this still needs to be tested in E. urophylla plants grown in high $\mathrm{CO}_{2}$ conditions and challenged by a broad spectrum of abiotic stressors.

Author contribution statement ACB carried out the experiment, processed the experimental data, analyzed the data and wrote the manuscript with support from TSB. BMS carried out the experiment and verified the analytical methods. TSB designed the study, supervised the project and contributed to the interpretation of the results. All authors read and approved the final manuscript.

Acknowledgements We thank Dra. Priscila Lupino Gratão from the São Paulo State University for providing the laboratory infrastructure for the quantification of $\mathrm{H}_{2} \mathrm{O}_{2}$ and MDA content analysis. This work had financial support from São Paulo Research Foundation-FAPESP (Grant number 2015/23354-8) and Coordination for the Improvement of Higher Education Personnel-CAPES.

\section{Compliance with ethical standards}

Conflict of interest The authors declare that they have no conflict of interest.

\section{References}

AbdElgawad H, Zinta G, Beemster GTS, Janssens IA, Asard H (2016) Future climate $\mathrm{CO}_{2}$ levels mitigate stress impact on plants: increased defense or decreased challenge? Front Plant Sci 7:556. https://doi.org/10.3389/fpls.2016.00556

ESRL - Earth System Research Laboratory (2017) national oceanic and atmospheric administration, trends in atmospheric carbon dioxide. https://www.esrl.noaa.gov/gmd/ccgg/trends/full.html. Accessed 16 Oct 2017

Farfan-Vignolo ER, Asard H (2012) Effect of elevated $\mathrm{CO}_{2}$ and temperature on the oxidative stress response to drought in Lolium 
perenne L. and Medicago sativa L. Plant Physiol Biochem 59:5562. https://doi.org/10.1016/j.plaphy.2012.06.014

$\mathrm{Hu}$ WH, Song XS, Shi K et al (2008) Changes in electron transport, superoxide dismutase and ascorbate peroxidase isoenzymes in chloroplasts and mitochondria of cucumber leaves as influenced by chilling. Photosynthetica 46:581-588. https://doi.org/10.1007/ s11099-008-0098-5

IPCC Panel (2014) Climate change: synthesis report. Contribution of working groups I, II and III to the fifth assessment report of the intergovernmental panel on climate change. IPCC, Geneva, pp 73-91

Kumari S, Agrawal M, Tiwari S (2013) Impact of elevated $\mathrm{CO}_{2}$ and elevated $\mathrm{O}_{3}$ on Beta vulgaris L.: Pigments, metabolites, antioxidants, growth and yield. Environ Pollut 174:279-288. https://doi. org/10.1016/j.envpol.2012.11.021

Liu Z, Chen W, He X, Fu S, Lu T (2015) Regulatory effects of elevated carbon dioxide on growth and biochemical responses to ozone stress in Chinese Pine (Pinus tabulaeformis Carr.). Bull Environ Contam Toxicol 97:793-797. https://doi.org/10.1007/s0012 8-016-1960-y

Michelet L, Zaffagnini M, Morisse A, Sparla F, Pérez-Pérez ME, Francia F, Danon A, Marchand CH, Fermani S, Trost P, Lemaire SD
(2013) Redox regulation of the Calvin-Benson cycle: something old, something new. Front Plant Sci 4:270

Mishra P, Bhoomika K, Dubey RS (2013) Differential responses of antioxidative defense system to prolonged salinity stress in salttolerant and salt-sensitive Indica rice (Oryza sativa L.) seedlings. Protoplasma 250:3-19. https://doi.org/10.1007/s0070 9-011-0365-3

Paoletti AC, Parmely TJ, Tomomori-Sato C et al (2006) Quantitative proteomic analysis of distinct mammalian Mediator complexes using normalized spectral abundance factors. Proc Natl Acad Sci USA 103:18928-18933. https://doi.org/10.1073/pnas.0606379103

Singh A, Agrawal M (2015) Effects of ambient and elevated CO2 on growth, chlorophyll fluorescence, photosynthetic pigments, antioxidants, and secondar metabolites of Catharanthus roseus (L.) G Don. grown under three different soil N levels. Environ Sci Pollut Res 22:3936-3946. https://doi.org/10.1007/s11356-014-3661-6

Zlatev ZS, Lidon FC, Ramalho JC, Yordanov IT (2006) Comparison of resistance to drought of three bean cultivars. Biol Plant 50:389394. https://doi.org/10.1007/s10535-006-0054-9 